\title{
Sistem Manajemen Operasional Jasa Travel Kendaraan Dalam Meningkatkan Pelayanan Perusahaan
}

\author{
Cahya Vikasari*) \\ Jurusan Teknik Informatika, Politeknik Negeri Cilacap, Cilacap \\ Jln.Dr.Soetomo No.1 Sidakaya 53212 Cilacap, Indonesia \\ email: cvikasari@gmail.com
}

Received: 9 Maret 2018; Revised:14 Mei 2018; Accepted: 15 Mei 2018

Copyright @2018 Politeknik Harapan Bersama Tegal. All rights reserved

\begin{abstract}
Car rental is a growing business that runs rapidly. Competition of travel business is getting strict and business development is getting rapidly. They can boost companies to improve quality and service to their consumers. The problem which always happens in processing travel business, i.e., manual data processing using book. It can give risk for losing data and duplication process, and also the data that does not automatically recapped until the report of income and other information are not up to date. It is needed that there is a system for supporting process of travel operational management. The method that used in the research was a method of software development, i.e., waterfall. The findings of the research is the system that can facilitate the process of travel operational management until it can make the available process more effective, improve the service to consumers, facilitate to search for data that relevant to vehicle travel data.
\end{abstract}

\begin{abstract}
Abstrak - Sewa mobil adalah usaha yang sangat pesat perkembangannya. Persaingan dalam usaha travel yang semakin pesat serta perkembangan bisnis yang semakin pesat mendorong perusahaan meningkatkan kualitas dan pelayanan kepada konsumennya.mPermasalahan yang terjadi dalam pengelolaan manajemen travel antara lain pengelolaan data yang masih manual menggunakan buku hal ini dapat berisiko kehilangan data dan proses duplikasi kegiatan serta perekapan data tidak secara otomatis sehingga laporan pendapatan dan informasi yang lain tidak up to date. Diperlukan adanya sistem untuk membantu mengelola manajemen operasioal travel kendaraan. Metode yang digunakan yaitu menggunakan metode pengembangan perangkat lunak yaitu waterfall. Hasil dari penelitian ini adalah sistem ini dapat mempermudah pengelolaan manajemen operasioal travel kendaraan sehingga dapat mengefektifkan proses yang ada, meningkatkan pelayanan kepada konsumen. mempermudah pada saat pencarian data yang berkaitan dengan data travel kendaraan.
\end{abstract}

Kata Kunci - Travel; waterfall; Manajemen.

\section{PENDAHULUAN}

Perkembangan zaman yang berubah menjadi lebih maju membuat perubahan perilaku konsumen dalam pemenuhan keinginan maupun kebutuhan sehingga akan membuat pelaku

*) Corresponding author: Cahya Vikasari

Email: cvikasari@gmail.com bisnis bersaing baik dalam bidang produk ataupun jasa. Bisnis barang dan jasa yang ditawarkan akan membuat peluang bagi konsumen untuk memilih produk atau jasa yang ditawarkan sesuai dengan keinginannya [1]. Bisnis di bidang transportasi sudah mulai berkembang dengan munculnya perusahaan baru dibidang travel kendaraan antar kota. Bisnis sewa mobil merupakan sektor bisnis yang termasuk pesat perkembangannya. Kehidupan dan kegiatan masyarakat yang sangat cepat membuat orandapat cepat pula dalam mencapai tujuan yang diinginkan dengan nyaman, mudah dan murah serta tidak menurunkan gengsi masyarakat sebagai pengguna jasa rental mobil. Dunia usaha dengan persaingan yang ketat dan perkembangan bisnis yang pesat membuat perusahaan penyewaan mobil senantiasa meningkatkan kualitas dari pelayanan kepada konsumen dengan tujuan perusahaan tersebut dapat bertahan dengan ketatnya persaingan dunia bisnis khususnya penyewaan mobil. Prinsip yang harus ditanamkan pengusaha yaitu kepuasan konsumen adalah tolak ukur dari keberhasilan perusahaan dalam menjalankan bisnisnya [2].

Masyarakat kini banyak yang sudah menggunakan jasa pengiriman. Kualitas pelayanan dari jasa pengiriman sangat penting agar dapat bertahan dalam dunia bisnis dan dapat memenangkan persaingan. Perusahaan harus mampu mengerti keinginan dan harapan dari konsumen mengenai kualitas pelayanan yang baik bagi konsumen. Kualitas pelayanan perlu mendapatkan perhatian yang lebih dari perusahaan karena kualitas pelayanan memiliki hubungan langsung dengan kemampuan perusahaan dalam bersaing dengan perusahaan sejenis selain itu kualitas pelayanan juga akan berimbas pada keuntungan perusahaan. Dalam mengutamakan pelayanan kepada konsumen maka diperlukan keakuratan dalam mendapatkan informasi dan kemudahan dalam mendapatkan informasi mengenai data kendaraan yang merupakan kebutuhan informasi dari perusahaan rental mobil agar usahanya dapat terlihat efektif dan efisien [3]. Di Indonesia saat ini masih banyak pengusaha rental mobil yang belum sepenuhnya memanfaatkan teknologi yang ada misalnya menggunakan web untuk pengelolaan data yang ada pada rental mobil. Dalam mengatur kebutuhan usaha rental mobil, perlu system informasi manajemen yang dapat membantu mempermudah semua kegiatan yang berhhubungan dengan rental mobil [4]. 
Pelayanan dalam perusahaan travel dapat ditingkatkan untuk memenuhi dan memuaskan pelanggan perusahaan travel. Pelayanan dalam bidang travel bersifat profit tetapi juga akan meningkatkan kepercayaan pelanggan terhadap perusahaan travel terhadap pelayanan yang diberikan. Dalam memulai peningkatan pelayanan perusahaan perlu berbenah mengenai permasalahan yang terjadi yang akan menghambat atau memperlambat proses pelayanan terhadap pelanggan. Permasalahan yang terjadi dalam pengelolaan manajemen travel yang masih melakukan pengelolaan data secara manual menggunakan buku hal ini akan menurunkan pelayanan dan kepercayaan pelanggan. Hal ini juga dapat berisiko kehilangan data dan proses duplikasi kegiatan serta perekapan data tidak secara otomatis sehingga laporan pendapatan dan informasi yang lain tidak up-to-date. Jika tidak didukung informasi yang baik dalam perusahaan travel kendaraan antar kota ini dapat mengakibatkan menurunnya pelayanan kepada konsumen yang akan menggunakan jasa ini dikatenakan data yang didapatkan bisa terdapat kekeliruan informasi. Begitu pula dengan proses pencarian data yang membuatuhkan watu lama dikarenakan masih dilakukkan secara manual. Diperlukan adanya sistem untuk membantu mengelola manajemen operasioal travel kendaraan sehingga dapat mengefektifkan proses yang ada dan dapat meningkatkan pelayanan kepada konsumen.

Isu yang ada dalam bisnis travel kendaraan yang pengelolaan datanya masih dilakukan secara konvensional akan memperlambat dalam proses pengelolaan data dan proses rekap serta mempersulit proses pencarian data sehingga proses pelayanan juga tidak maksimal. Hipotesis penelitian yaitu dengan menggunakan aplikasi untuk membantu dalam manajemen oprasional perusahaan travel kendaraan akan meningkatkan pelayanan kepada konsumen. Tujuan penelitian mengenai sistem manajemen oprasional yaitu dapat merancang dan membangun aplikasi yang mampu membantu mengelola manajemen operasional travel kendaraan sehingga dapat mengefektifkan proses yang ada dan dapat meningkatkan dan mempercepat proses pelayanan kepada konsumen, memudahkan dalam pengelolaan data dalam manajemen perusahaan, mempermudah pada saat pencarian data yang berkaitan dengan data travel kendaraan.

\section{PENELITIAN YANG TERKAIT}

Penelitian yang dilakukan oleh Cahyono, Sukadi (2014) mengenai sistem informasi rental mobil pada purnama rent car berbasis web. Jasa penyewaan mobil merupakan bisnis yang sangat menguntungkan dengan modal beberapa kendaraan seseorang dapat membuka usaha penyewaan mobil yang dapat digunakan oleh konsumen untuk berbagai keperluan. Masalah yang ada dalam usaha penyewaan mobil yang pengelolaan datanya masih dilakukan secara konvensional yaitu informasi kendaran kepada konsumen tidak up-to-date, data tidak tersusun dengan rapi serta data kurang akurat. Tujuan penelitian yaitu dapat menghasilkan sistem informasi penyewaan mobil yang dapat melakukan pemesanan melalui website [3].

Penelitian yang dilakukan oleh Arifin (2016) mengenai portal penyewaan mobil online yang membahas tentang kegiatan pemesanan sewa mobil pada beberapa penyewaan mobil yang belum menerapkan sistem terkomputerisasi secara optimal dalam menangani pemesanan sehingga dapat terjadi permasalahan pada beberapa proses yang ada dalam perusahaan tersebut antara lain pemesanan melalui telepon yang dapat terjadi kurangnya informasi mengenai rinciam kendaraan yang akan dipesan dan pengelolaan data penyewaan mobil dengan menggunakan buku dalam pembukuannya akan mengakibatkanhilangnya data sewa mobil dengan berbagai sebab. Sistem buat dengan bahasa pemrograman PHP, dirancang dan dimodelkan dengan pemodelan UML (Unified Modelling Language) yang diharapkan dalam pembangunan system ini yaitu peran aplikasi yang dapat menggantikan peran dari perusahaan rental kendaraan. Pengambilan data dalam penelitian yaitu melaksanakan observasi lapangan, melakukan wawancara dengan beberapa pengelola rental mobil, dan menggunakan literatur dan teori yang mendukung dalam membangun aplikasi. Aplikasi ini dibangun untuk mempermudah dalam melakukan penyewaan mobil bagi konsumen dan bagi pengusaha rental mobil dapat digunakan untuk mengembangkan usahanya dengan menggunakan mekanisme sistem penyewaan mobil [5].

Perbedaan dengan penelitian sebelumnya yaitu pengembangan aplikasi pada penyewaan rental mobil difokuskan pada peningkatan pelayanan perusahaan rental mobil kepada konsumen sehingga dapat lebih efektif dan efisien. Penjadwalan dan ketersediaan kursi secara up-to-date dalam layanan rental mobil akan ditekankan untuk menunjang informasi yang akurat.

\section{A. Bahan Penelitian}

\section{METODE PENELITIAN}

Bahan penelitian diperoleh setelah melewati tahap perencanaan yaitu dengan melaksanakan observasi di lapangan, wawancara dengan pihak terkait dan mencari literature yang sesuai dengan pembangunan sistem [6]. Bahan penelitian yang diperlukan antara lain:

- Data konsumen, data mobil, data sopir dan data trayek travel.

- Proses bisnis manajemen dan pelayanan travel kendaraan.

- Jadwal travel dengan trayek antar kota

\section{B. Tahap Pengembangan Sistem}

Menurut Rosa (2011) tahap pengembangan sistem ini menggunakan metode pengembangan perangkat lunak model waterfall. Model waterfall atau SDLC juga sering disebut dengan model sekuensial linear. Model ini menyediakan pendekatan alur hidup aplikasi secara konsekuensial atau secara terurut dengan tahapan analisis, desain, pengkodean, pengujian serta tahap support [7]. Tahap pengembangan system menggunakan metode waterfall dapat dilihat pada Gbr. 2.

\section{A. Analisis Kebutuhan}

Menurut Bhaskaraputra (2014) kegiatan analisis kebutuhan adalah kegiatan yang mengawali dalam menentukan gambaran perangkat lunak yang nantinya akan dihasilkan ketika pengembang perangkat lunak melaksanakan proyek dalam pembuatan perangkat lunak. Hasil perangkat lunak yang baik yaitu yang sesuai dengan kebutuhan pengguna yang sangat tergantung pada keberhasilan tahap analisis kebutuhan [8]. Hasil analisa kebutuhan pengguna 
dapat dilihat pada tabel I analisa kebutuhan sistem.
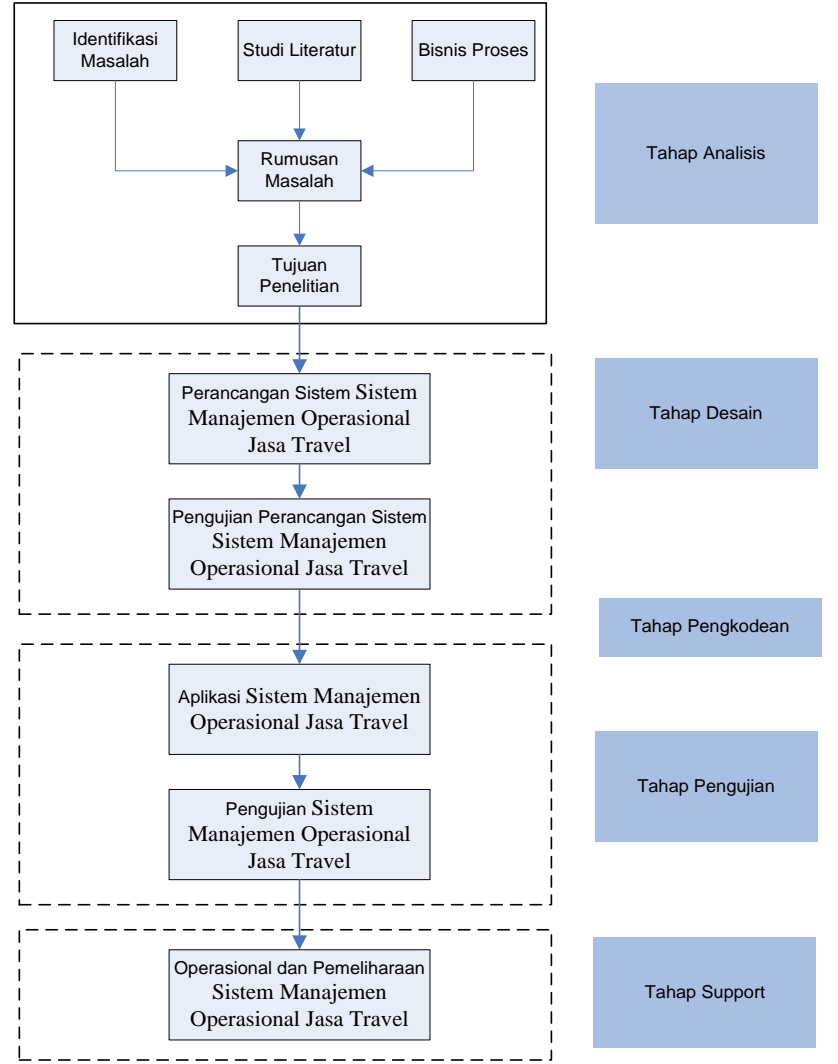

Gbr. 2 Tahapan Penelitian dengan Metode Waterfall

TABEL I

ANALISA Kebutuhan Sistem ManaJemEn OpRasional JASA TRAVEL KENDARAAN

\begin{tabular}{|l|l|}
\hline $\begin{array}{c}\text { Kategori } \\
\text { Pengguna }\end{array}$ & \multicolumn{1}{|c|}{ Aktivitas } \\
\hline Manager & Melihat laporan \\
\hline Admin & $\begin{array}{l}\text { Mengelola data pegawai, data mobil,data } \\
\text { rute, data trayek, dan data jadwal. }\end{array}$ \\
\hline Pegawai & $\begin{array}{l}\text { Dapat melakukan ubah password, input } \\
\text { laporan pemesanan, input laporan } \\
\text { pembatalan, cetak struk pemesanan dan cetak } \\
\text { struk pembatalan. }\end{array}$ \\
\hline
\end{tabular}

\section{B. Perancangan}

Menurut Prihandoyo (2018) perancangan menggunakan Unified Modeling Language yang merupakan salah satu metode pemodelan visual yang digunakan dalam perancangan dan pembuatan sebuah software yang berorientasikan pada objek. UML merupakan sebuah standar penulisan atau semacam blue print dimana didalamnya termasuk sebuah proses bisnis, penulisan kelas-kelas dalam sebuah bahasa yang spesifik [9]. Diagram yang dipakai yaitu digram usecase yang akan menggambarkan fungsi-fungsi yang terdapat dalam sistem dan diagram class yang akan menggambarkan hubungan antar class yang ada.

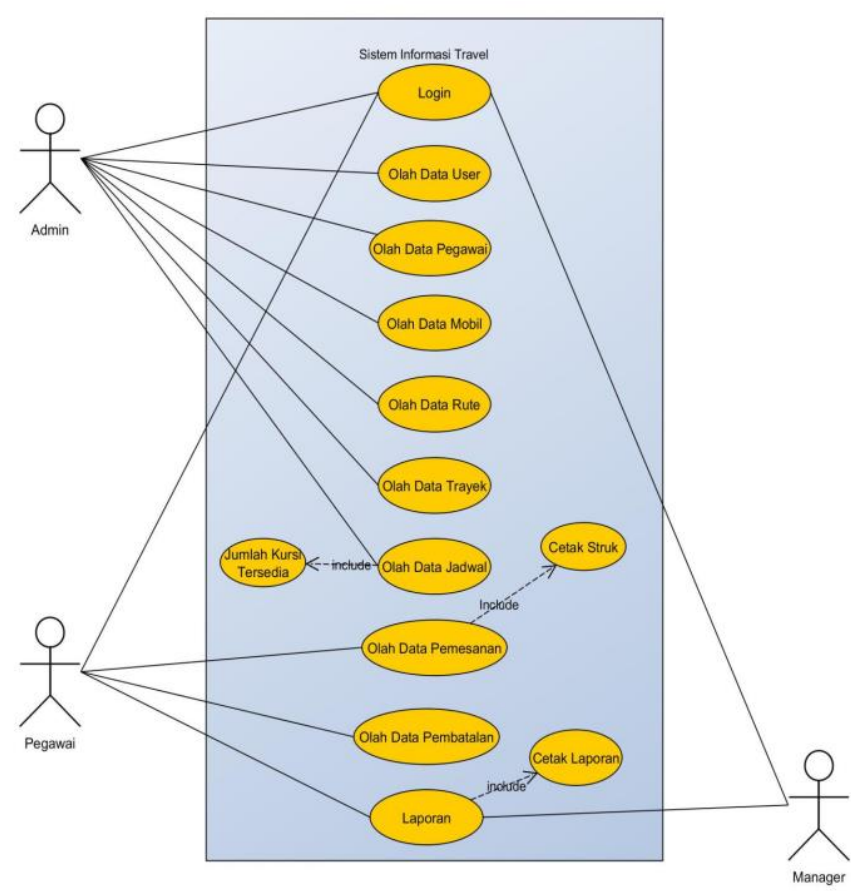

Gbr. 3 Use case Diagram

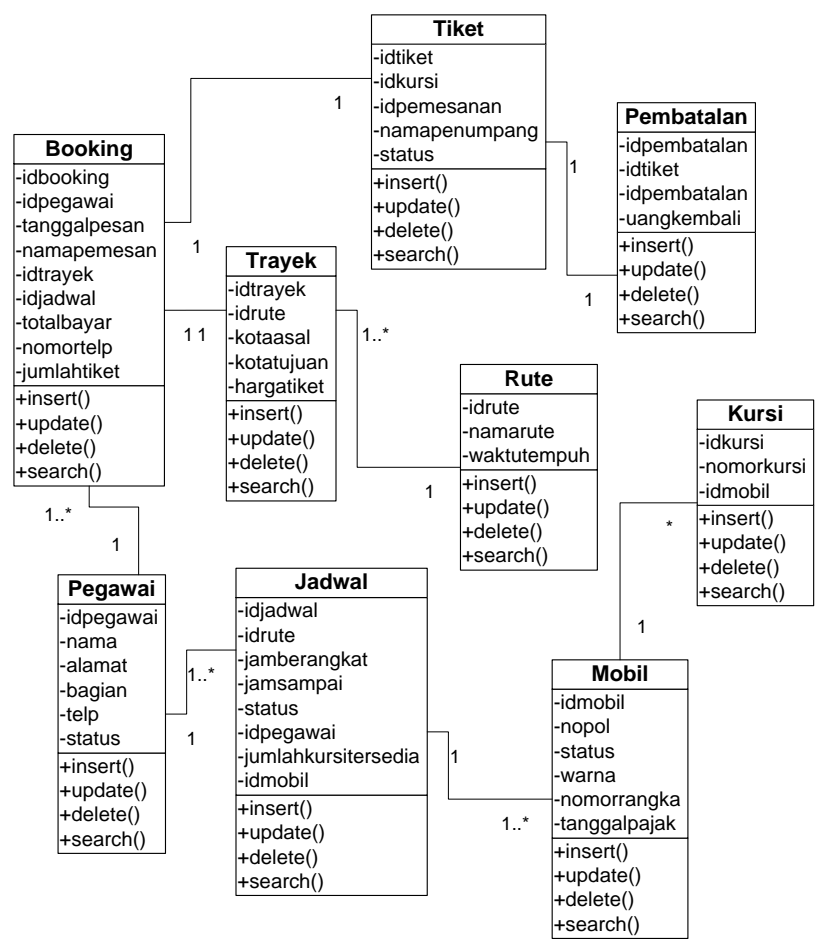

Gbr. 4 Class Diagram

\section{1) Usecase}

Menurut Satzinger (2011) perancangan sebuah aplikasi dibuat sesuai dengan analisis kebutuhan yang diperoleh. Pembuatan sistem ini, penulis menggunakan pemodelan usecase diagram. Usecase diagram adalah serangkaian tindakan yang akan dilakukan oleh sistem, actor yang akan mewakili user atau sistem lain yang dapat berinteraksi dengan model dari system yang dimodelkan [10]. Berikut ini merupakan gambar diagram use case dalam merancang sistem manajemen operasional jasa travel kendaraan dalam 
meningkatkan pelayanan perusahaan dapat dilihat poada gambar 3.

\section{2) Class Diagram}

Class diagram merupakan diagram yang bertugas mendeskripsikan jenis-jenis objek dalam sebuah sistem serta berbagai macam hubungan statis yang terdapat diantara mereka. Class diagram bertugas memperlihatkan property serta operasi sebuah class dan batasan-batasan yang terdapat dalam hubungan objek-objek tersebut [11]. Dibawah ini merupakan gambar class diagram untuk menggambarkan struktur sistem yang akan dibuat untuk sistem manajemen oprasional jasa travel kendaraan dalam meningkatkan pelayanan perusahaan dapat dilihat pada Gbr 4 .

\section{HASIL DAN PEMBAHASAN}

\section{A. Hasil Penelitian}

Penelitian akan menghasilkan hasil-hasil penelitian dapat dilihat dari antar muka sistem yang telah dibuat yaitu pada Gbr.5. Gbr. 5 merupakan user interface pengelolaan data pegawai yang ada di perusahaan travel kendaraan. Pengelolaan data pegawai sangat diperlukan karena akan digunakan sebagai informasi setiap ada proses pemesanan tiket dengan tujuan agar dapat memberi info mengenai siapa yang menerima booking dari pelanggan.

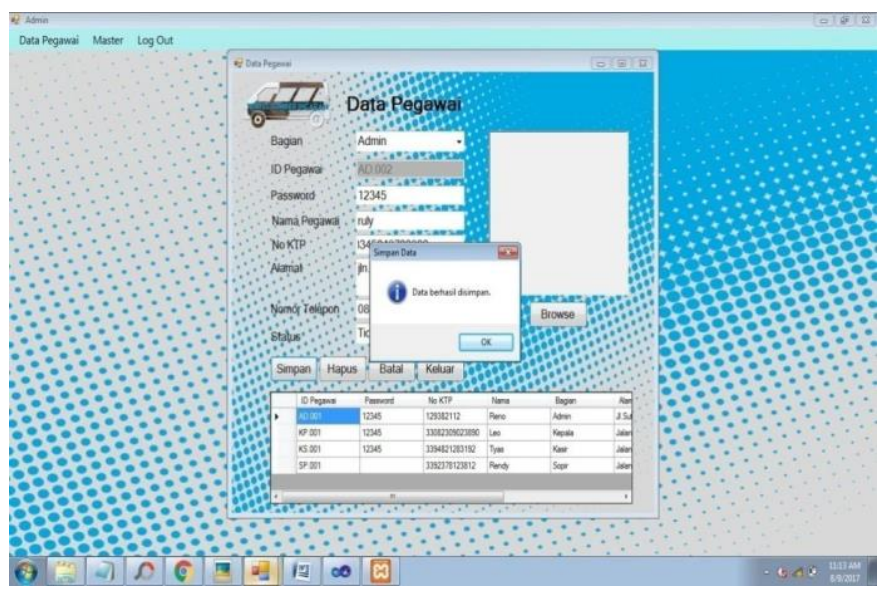

Gbr. 5 Antarmuka pengolahan data pegawai

Pada Gbr 6 merupakan tampilan yang dapat dikelola untuk mengelola data mobil yang merupakan aset dari perusahaan sehingga diwajibkan untuk mengisikan dengan lengkap data mobil yang diperlukan. Gbr. 7 merupakan pengelolaan data rute yang akan dilayani oleh perusahaan travel. Data rute ini dapat digunakan oleh pegawai untuk memberikan informasi ke pelanggan mengenai rute yang ada di perusahaan sehingga pegawai dapat memberikan data yang akurat mengenai informasi rute.

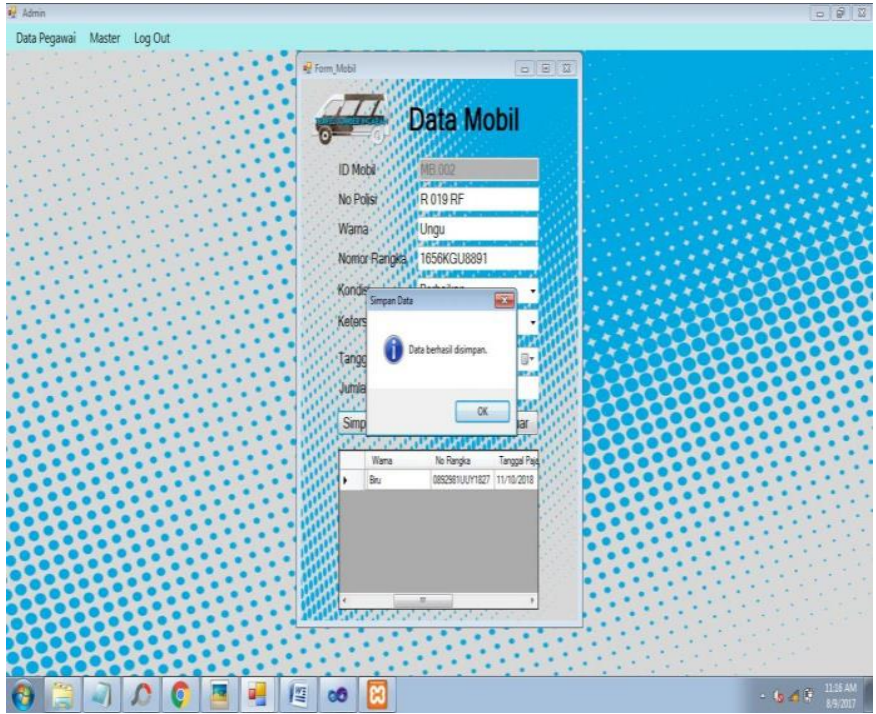

Gbr. 6 tampilan sistem pengolahan data mobil

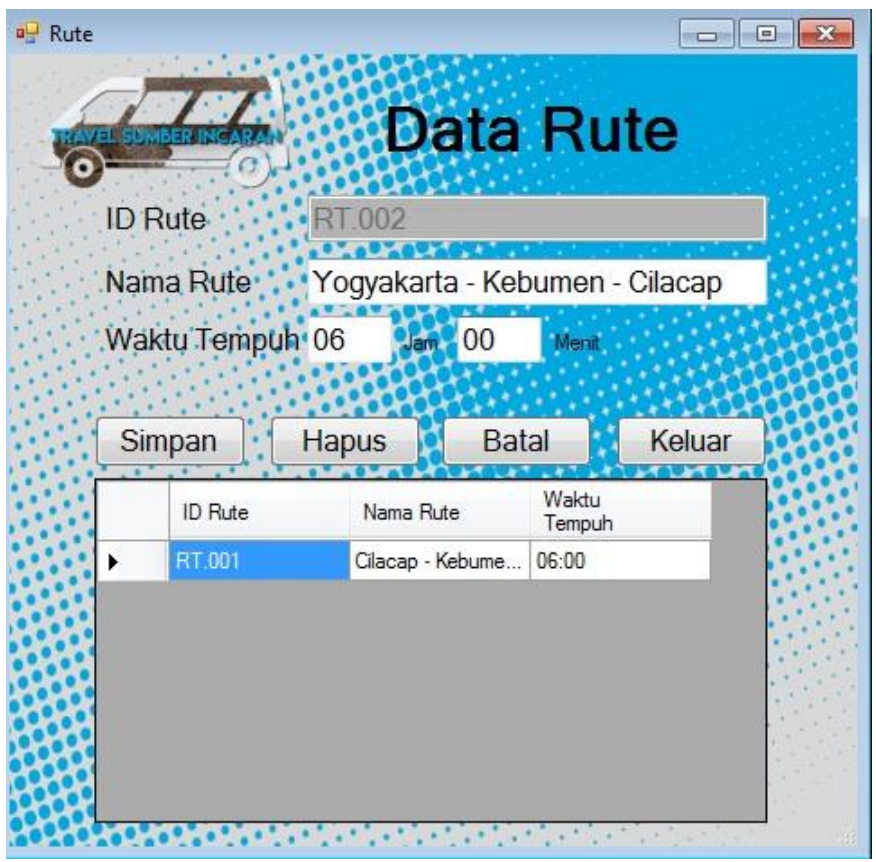

Gbr. 7 Antarmuka pengolahan data rute

Pada Gbr. 8 admin dapat melakukan pengelolaan data trayek sesuai dengan rute yang ada. Setiap rute dapat dikerjakan oleh beberapa trayek setiap harinya. Pelayanan informasi semakin lengkap oleh pegawai kepada pelanggan dengan informasi trayek yang ada pada sistem. Pada Gbr. 9 pengelolaan data jadwal diperlukan untuk keakuratan data pada saat menawarkan jasa travel kepada pelanggan. Pengelolaan data jadwal antara lain mengisi data rute, kursi tanggal berangkat, sopir yang bertugas membawa mobil travel.sesuai dengan jadwalnya. 


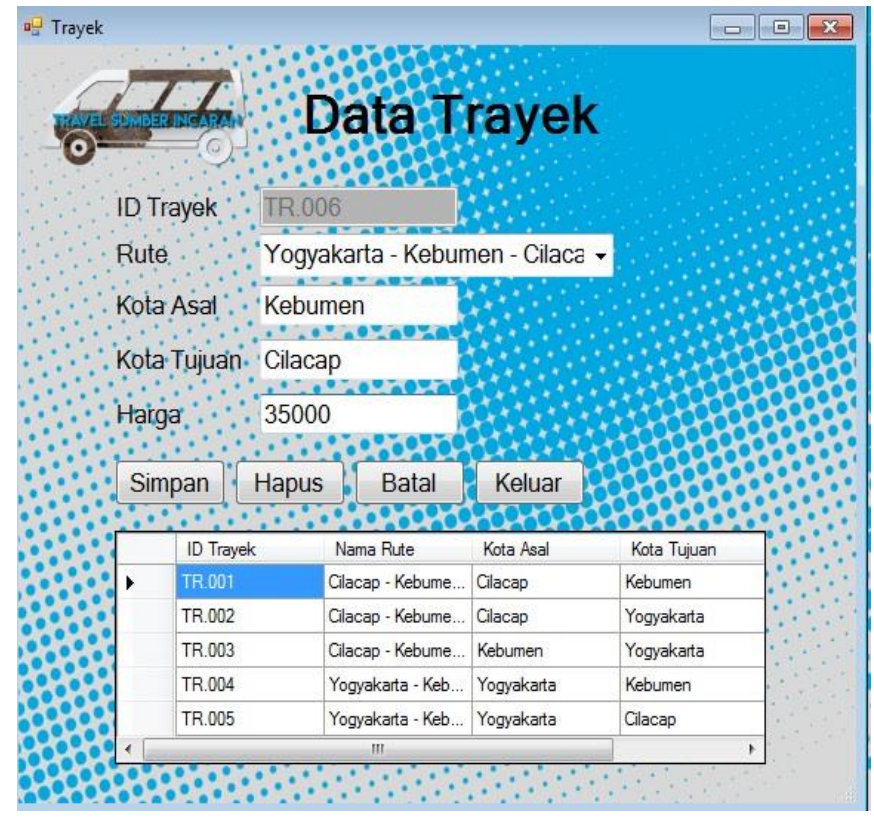

Gbr. 8 Halaman pengolahan data trayek

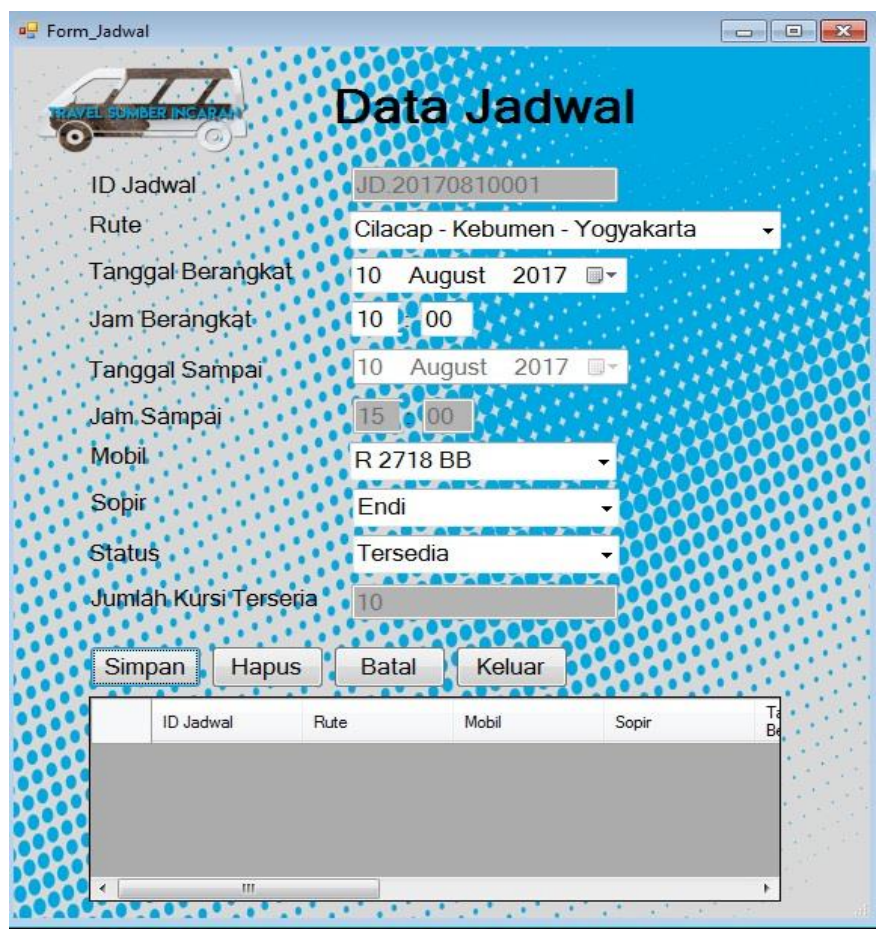

Gbr. 9 Halaman pengolahan data jadwal

Gbr.10 merupakan halaman pengolahan data pemesana dimana pemesanan akan dikelola oleh kasir pada saat ada pelanggan yang melakukan pemesanan tiket jasa travel. Pelanggan akan diberi id pemesanan dan melengkapi data pemesanan seperti nama, nomor telepon, memilih rute, dan memilih jadwal serta memilih kursi tempat duduk yang dipesan. Pada Gbr.11 pelanggan berhak melakukan pembatalan pemesanan sesuai dengan persyaratan perusahaan. Kasir memasukan nomor tiket pelanggan atau dapat mencari data tiketnya jika terjadi kehilangan data tiket oleh pelanggan. Proses berikutnya adalah kasir akan melakukan pemilihan tombol batalkan tiket dan data kursi akan berubah menjadi tersedia sesuai dengan jumlah tiket yang dibatalkan.

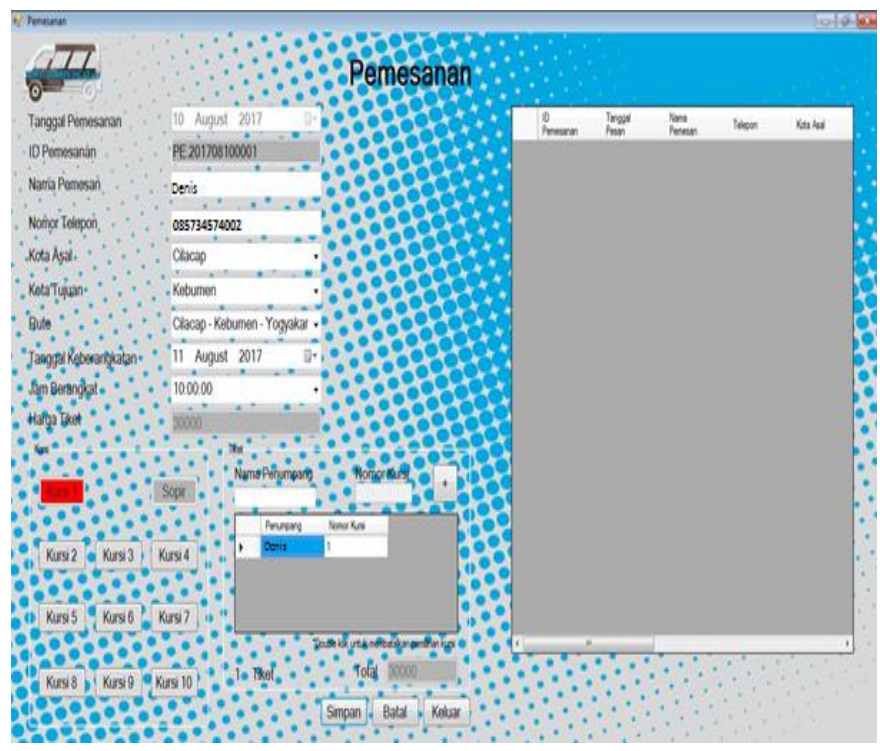

Gbr. 10 Halaman pengolahan data pemesanan

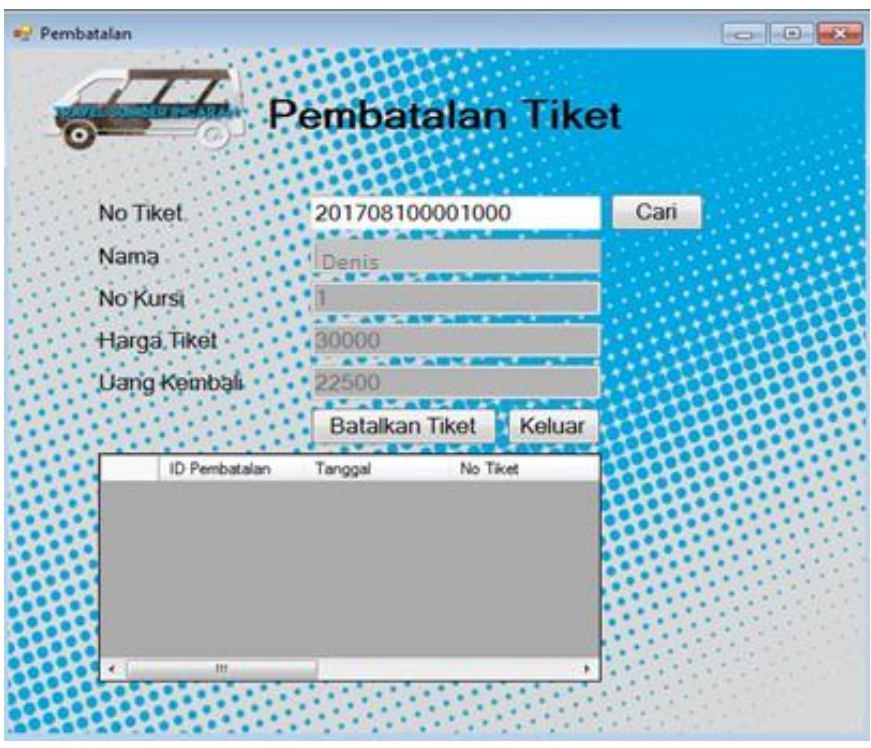

Gbr. 11 Halaman pengolahan data pembatalan

\section{B. Hasil Penelitian}

Sistem manajemen operasional jasa travel kendaraan ini digunakan oleh perusahaan jasa travel dengan beberapa user yang dapat menggunakan aplikasi tersebut antara lain admin yang akan mengolah data dasar, pegawai yang akan melakukan bagian oprasional pada front office sehingga sangat membutuhkan system yang dapat membantu mempercepat pelayanan kepada konsumen. Sedangkan manager dapat melihat laporan transaksi yang ada sehingga dapat mempercepat analisis terhadap data transaksi yang ada. Aplikasi ini dapat mengefektifkan proses manajemen pada perusahaan tersebut sehingga mampu mengefektifkan proses yang ada dalam mendukung sisi pelayanan kepada konsumen 
serta dapat meningkatkan dan mempercepat pelayanan. Data yang ada langsung dikelo dengan system sehingga data-data yang diperlukan lebih up to date misalnya data jadwal pemberangkatan mobil travel dan ketersediaan kursi untuk setiap jadwal pemberangkatan. Dua Informasi inilah yang sering dibutuhkan oleh konsumen sehingga pegawai harus cepat dalam memberikan pelayanan mengenai informasi tersebut.

Ketersediaan kursi akan terlihat apa saat akan dilakukan pemesanan dengan perbedaan warna untuk menunjukan status dari kursi apakah sudah dipesan atau belum. Bukan hanya pemesanan dan informasi yang cepat namun pembatalan pemesanan juga dapat ditangani oleh sistem sehingga konsumen juga akan terlayani dengan baik dan tidak akan dirugikan sehingga sistem dapat memberikan perubahan pada status kursinya menjadi kosong kembali. Sistem yang akan membantu perusahaan travel juga berperan besar dalam sisi pelayanan prima sebuah perusahaan travel dan konsumenpun dapat melihat pelayanan prima tersebut. Selain itu peningkatan sisi pelayanan perusahaan dengan didampingi dengan sistem untuk kegiatan oprasional juga dapat berakibat penerimaan provit dari perusahaan tersebut dan repeat order dari para konsumen.

\section{KESIMPULAN}

Kesimpulan dari kegiatan penelitian mengenai sistem manajemen operasional jasa travel kendaraan dalam meningkatkan pelayanan perusahaan yaitu mempermudah pengelolaan manajemen operasional travel kendaraan sehingga dapat mengefektifkan proses yang ada. Selain meningkatkan pelayanan kepada konsumen dengan informasi mengenai data travel yang up-to-date, mempermudah pada saat pencarian data yang berkaitan dengan data travel kendaraan.

\section{UCAPAN TERIMA KASIH}

Ucapan terimakasih yang sebesar-besarnya kepada pihak-pihak yang secara langsung maupun secara tidak langsung yang membantu penulis dalam menyesaikan penelitian mengenai system manajemen oprasional jasa travel kendaraan, penulis mengucapkan terimakasih kepada Politeknik Negeri Cilacap yng telah memeberikan ruang dan tempat melaksanakan penelitian.

\section{DAFTAR PUSTAKA}

[1] Reza Dimas Sigit P and Farah Oktafani, "Pengaruh Kualitas Pelayanan Terhadap Kepuasan Pelanggan Pengguna Jasa Lapangan Futsal (Studi Kasus Pada Ifi Futsal Bandung )," J. Univ. Telkom, no. September, 2014.

[2] I. Septavia, R. E. Gunadhi, and R. Kurniawati, "Sistem Informasi Penyewaan Mobil Berbasis Web," J. Algoritm., vol. 13 No. 1, pp. 1-8, 2005.

[3] J. T. Cahyono, "Pembuatan Sistem Informasi Rental Mobil Purnama Rent Car Ploso Pacitan Berbasis Web," Indones. J. Netw. Secur., vol. 3, no. 1, pp. 47-52, 2014.

[4] D. Agustia, T. Suci, I. Inayati, and C. Darujati, "Sistem Informasi Manajemen Rental Mobil ( Studi Kasus: Sewan Id ),” vol. 2, no. 2, 2017.

[5] A. Muhammad, P. L. Mahendra, and P. K. Handayani, "Fakultas Teknik - Universitas Muria Kudus 295," Pros. SNATIF, no. 2003, pp. 295-302, 2016

[6] Neti, E. Cofriyanti, and R. Angraini, "Perancangan aplikasi rental mobil pada cv karya bersama palembang," STMIK-MD

[7] A.S Rosa and S. M, Modul Pembelajaran Rekayasa Perangkat Lunak (Terstruktur dan Berorientasi Objek). Bandung: Modula, 2011

[8] bhaskaraputra, "Analisa Kebutuhan Perangkat Lunak," 2014.

[9] M. T. Prihandoyo, "Unified Modeling Language ( UML ) Model Untuk Pengembangan Sistem Informasi Akademik Berbasis Web," $J$. Inform. J. Pengemb. IT, vol. 3, no. 1, pp. 126-129, 2018.

[10] R. B. J. and S. D. B. J. W. Satzinger, Systems Analysis and Design in a Changing World, Sixth. 2011

[11] Modulmakalah, "Pengertian Class Diagram, Kegunaan, dan Contoh Menurut Para Ahli," 2017. [Online]. Available: http://modulmakalah.blogspot.co.id/2017/01/Pengertian.Class.Diagra m.Kegunaan.dan.Contoh.Menurut.Para.Ahli.html. 